Volume 10, No.6, November - December 2021

International Journal of Advanced Trends in Computer Science and Engineering

Available Online at http://www.warse.org/IJATCSE/static/pdf/file/ijatcse081062021.pdf

https://doi.org/10.30534/ijatcse/2021/081062021

\title{
An Effective Health Information Management System for Optimal Healthcare Delivery
}

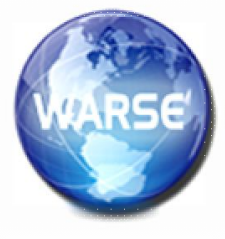

\author{
Abiola O.B ${ }^{1}$, Oguntimilehin $\mathrm{A}^{2}$, Tope-Oke A.M ${ }^{3}$, Babalola G.O ${ }^{4}$ \\ ${ }^{1}$ Afe Babalola University, Ado-Ekiti, Nigeria, abiolatoyinbunmi@gmail.com. \\ ${ }^{2}$ Afe Babalola University, Ado-Ekiti, Nigeria, abiodunoguns@ abuad.edu.ng. \\ ${ }^{3}$ Afe Babalola University, Ado-Ekiti, Nigeria, topeokea@ abuad.edu.ng. \\ ${ }^{4}$ Afe Babalola University, Ado-Ekiti, Nigeria, gbemibabz@abuad.edu.ng.
}

Received Date : October 09, 2021 Accepted Date : November 09, 2021 Published Date : December 06, 2021

\begin{abstract}
The effect of security of health information on patients as well as the society at large cannot be overemphasized. If information gets to the wrong hands, it can lead to various disaster ranging from blackmail, financial loss, stigmatization, medio-legal issues and ultimately death. This research work addresses the problems associated with existing records management system in Federal Teaching Hospital, Ekiti State Nigeria (FETHI), which is manual based. At present, approach to file handling involves junior cadre staff moving files between departments and this is often subject to various degree of mishandling which could lead to loss of important documents, leakage of confidential information among others. The model proposed and implemented in this research addresses the issue of security and privacy in health information system and proffer advantages such as easy storage and retrieval, easy transfer of patients 'records and it also guarantee confidentiality of information at all stages. The user-friendly web-based system was developed using Hypertext Preprocessor (PHP) as the front -end and MySQL as the backend.
\end{abstract}

Key words: Patients 'Records, Health Information, Management Systems.

\section{INTRODUCTION}

Patients' records otherwise known as medical records are the scientific collections or documentations of a person's healthcare information over a period of time within the jurisdiction of a particular healthcare provider. This information includes bio-data, medical history, health related family and social history, drugs and medication history, surgical and treatment history, billing and financial records etc. [5].

Since the successful takeover of the medical records practice from the expatriates in 1964 by Nigerians, there have been several attempts to standardize health records management and ensure security and confidentiality of health records. This led to the establishment of training schools in Nigeria for continuous training of medical records professionals.
Association of Medical Records and Information Management Practitioners in Nigeria (first known as Nigerian Health Records Association) was also established for the purpose of

Improvement of the practice. There have been several attempts by researchers to implement and deploy health information management systems

[1] worked on information security and privacy in healthcare. They were motivated by the need to ensure information security in the healthcare system especially from the inside. They provided a holistic view of the recent research and suggested new areas of internet to the information systems community but they did not develop a framework to ensure information security.

[3] explored security challenges in healthcare cloud computing. They were motivated by the need for health information security in progressed technologies as cloud computing which are vulnerable to cyber gaps that pose an adverse impact on the security and privacy of patients' electronic health records. It was discovered that for ensuring healthcare information security, it is important to provide authentication, authorization and access control within cloud's virtualized network but attempt was not made to provide a model that will guarantee information security.

[6] examined how to conquer security and privacy issues in healthcare services with the introduction of Telemedicine. They were motivated by the advancement in telecommunication combined with improved information technology infrastructures. It was revealed that the issue of security and privacy has now become a thing of concern with the introduction of telemedicine. However, their work did not proffer a better way of ensuring information security through an ICT framework.

\section{MOTIVATION}

This study examined the age long issue of security and confidentiality of patients' records in Federal Teaching Hospital Ido Ekiti, Nigeria and how it affects quality of healthcare delivery and seek to proffer solutions to the problem, considering the fact that health records is the foundation on which successful healthcare delivery rests. The Federal Teaching Hospital Ido Ekiti, evolved from a General 
Hospital in 1978 to a Federal Medical Centre in 1999 and then to Federal Teaching Hospital in 2014, (to serve as the health training arm for Afe Babalola University, Ado Ekiti). Today, Federal Teaching Hospital Ido Ekiti is a Multi Clinic Tertiary Institution with seventeen clinical and thirteen non clinical departments. It would be of great benefit to conduct a detailed study on the records keeping and management processes or systems used by the facility, as well as the security challenges of the existing system and proffer a new system to have positive impact. The manual method of handling patient health records is marred with so many challenges such as slow and tedious manual processing, prolonged waiting time for patients, lack of backup for available records and most especially, lack of adequate security of patient information which if left unattended to can result in medical-legal issue and breach of trust on the part of the Hospital management. However, limited studies have been conducted to examine electronic model for health information security in (FETHI).

The existing health records management system in Federal Teaching Hospital Ido Ekiti is a manual system. Such a system (as it is the characteristic) is usually without any form of backup, it provides little or no reliable security for patients' healthcare data. Problems associated with this system includes but not limited to: lack of security for patients records, slow and tedious manual processing, prolonged waiting time for patients, lack of backup for available records, replication of records across clinics, lack of control on access to health records, unavailability of existing records when needed and many others. Consequently, there are issues of data loss, data theft, financial loss to patients and hospital, loss of patients' confidence in the hospital, litigation arising from misuse of information and even loss of human life.

\section{ANALYSIS OF THE EXISTING SYSTEM}

In (FETHI) Ido Ekiti, Nigeria Patients' health records are still manually managed. In this system, every patient is allocated a paper file (known as Case Note) with unique Hospital Number and patient's name clearly written on the outer cover for identification. The Case Note houses all records of the patient to which it belongs. Such records include demographics, clinical history and treatment records (including type of disease(s), family history, social and behavioral history, medication, surgical operation etc.), hospitalization or admission records, medical tests or investigation records (like laboratory test results, X-ray reports, pathology reports.), billing and financial records etc. All Case Notes are centrally stored in a central medical record library, arranged chronologically by the hospital numbers. Case Notes are retrieved from the shelf and taken to the clinic when needed and are returned to the shelf (filed) when all operations involving them are completed. This process is referred to as Filing and Retrieval

\section{a. Case Notes Handling Procedure}

Because the Case Note is the primary store where all healthcare information of a patient is kept, it is meant to be handled with utmost care. There are tools, policies and precautions guiding handling of patients' Case Notes to ensure the information kept in them are safe and available when needed. For example, Case Notes must never be handled by patients or any other person than hospital clinical staff (this instruction is boldly printed on the outside cover of each Case Note). For effective management, there are other tools used for documentation and keeping records of clinical activities. Such tools are part of the overall management of Case Note movement and access control. Examples include: the tracer card, the movement register, clinic attendance registers etc.

\section{b. Retrieval Process}

By default, the primary reason why a Case Note should be retrieved is when the patient to whom the records belong visits the clinic for healthcare service. The other reason for this action is when the Case Notes is required for an investigation or study (by the hospital or hospital staff with a clearance to do so) that require extracting information from the Case Note. Whichever the case is, the hospital number of the Case Note is supplied to the library manager (health records officer manning the library), who searches for the required Case Notes, if found, he or she fills out movement information on a Tracer Card (a small card which carries the name and number of the same file, used to document the movement of the file) and placed in the position from where the Case Note was retrieved and makes an entry in a Movement Register (a register which is used to document movement of all Case Notes in the Library) indicating that the Case Note has been retrieved and given out. The register contains the following fields: file number, name, date and time retrieved, clinic sent to, reason for the retrieval, requesting officer, handled by (the hospital attendant transporting the Case Note), date and time returned (left blank during retrieval).

\section{c. Filing Process}

After the treatment of each patient, the Case Note is sent back to the library in medical records department. Upon receipt, the library manager ensures that all documents are well arranged and stringed or clipped to the file jacket, the register is filled indicating date and time of return, then the file is returned to its position on the shelf.

\section{d. File Tracing}

In case a Case Note does not return to the library, the library manager relies on the Tracer Card and the Movement Register to locate the file. The destination of the Case Note documented on the last retrieval log entry will be the first place to check. If the Case Note is not found at the location, a further search will be carried out by reviewing activities carried out at that clinic on the patient as well as making enquiries from members of staff at the clinic. If the Case Note is not found, the officer who requested for it shall be held responsible for the loss.

In the clinic, the Clinic attendance register is filled when a patient visits the clinic and the Case Note is successfully 
retrieved. The health records officer, documents the visit to indicates that the patient actually visited the clinic. In the case of an admitted patient, admission and discharge register are maintained in the wards to document date and time of patient's admission and discharge. The records in these registers justify the movement of the Case Notes and serve as pointers to the actual location of the Case Note.

However, the manual method of handling patients' Health Records is marred with serious challenges one of which is data security. For example, once a patient's Case Note is handed over to a person, the entire data of that patient is in his or her hands, at that point, he or she can do whatever he or she wants with such records, just like anything can happen between the origin (where the Case Note was collected) and the destination (where it is going). If the courier decides to make a copy of the entire data records for his or her personal use (or even outright sale to an interested party), this can be achieved successfully as there is no mechanism to track or checkmate what happens between the origin and the destination.

In a bid to provide solution to the issue of security in health records management in (FETHI), an electronic health records management system is proposed in this research work. This new system will provide security for patients' health records. This shall be achieved by ensuring that only authorized persons have access to health records, as well as limiting access to only what is needed at a time. Consequently, this study focuses on the level of security of patient health records under the current system and the need to provide better security and mechanism to track and checkmate patients' health records.

\section{AIM AND OBJECTIVES}

This study is limited to the development of electronic health records management system for (FETHI). The aim of this study is to develop health information management system. The specific objectives are to:

a. Design a health information management system

b. Implement the system designed in (a).

\section{ANALYSIS OF THE PROPOSED SYSTEM}

The system proposed in this research project is expected to facilitate paperless exchange of information, patient record in particular, among various stakeholders within the health institution in a secure manner. Major actors within the system include: record officer(s), nurses, doctors and patients. Each actor play a major role directly or indirectly in order to achieve the objective of record keeping in a health institution. Due to the fact that past medical record often play a vital role in diagnosis and prescription in medicine, there is need for proper capturing of medical history, storage and archiving, and then retrieval for future use.

In general, health record is created at the point where a potential patient approaches the record unit to open a file. The record unit is responsible for assigning hospital number to patient, and then documents their bio-data. Further activities on the new record can then be initiated whenever the patient requires the service of the health institution. The record officer is expected to retrieve the patient's record and then forward same to the nurses' desk where patient vitals are taken and such patient is assigned to a medical doctor who can access the patient's history and also update the patient's file based on complaint, symptoms, diagnosis, prescribed laboratory tests and medication. Nurses and Record officers are not expected to have access to content of patient file while provision for easy searching and retrieval process is to be made for doctor to easily search through medical details. The following are the specifications the proposed system must meet

\section{a. Functional Requirements}

The proposed application must be able to perform the following task:

i. Create record of new patient

ii. Transfer patient record between different categories of users

iii. Maintain up-to-date audit report of the activity of each user on the system

iv. Enable easy access to patient's record through a robust search mechanism

v. Allow doctors and nurses to be able to update patient's record based on defined access control list

vi. Allow system administrator to create and manage various categories of users

vii. Generate reports on patient, doctor, nurse, etc.

viii. Allow medical doctors access to patient's medical history

\section{b. Non-functional Requirements}

Aside the functional requirements of the system highlighted already, the following non-functional requirements are necessary for smooth running of the system.

i. The developed application must be easy to use for users who are not computer experts with minimal training

ii. The application must be secured; that is, have mechanism for protecting sensitive data

iii. The system should also provide a mechanism for regular backups in order to facilitate recovery after system failure.

\section{METHODOLOGY}

The methods of study adopted in this work include; review of related literatures, problem identification and data collection within the subject domain. The hardware requirement of the system relies on a 3-tier web based architecture which comprises of the server, the middleware and front end. The application server is expected to house the program while client access the application via browser. The software requirement application runs on web servers like APACHE, Tomcat and the recommended operating system on the server is Linux. The client needs a web browser such as Mozilla Firefox running on any operating system. 
The programming language used in the implementation of this work is PHP as front-end and MySQL as back-end. PHP is faster and features a rich Open Source scripting language used to develop web application while MySQL is a powerful Open Source data based server built based on a relational database and it can handle large concurrent database connection. The combination of the two for application development offers clean and simple usability, complex functionality, speed, power and scalability. The health record management system developed captures four categories of users which include the System Administrator, the Record Officer, the Doctor and the Nurse.

\section{a. System Architecture}

The proposed architecture as delineated in Figure 1 is made up of a central database file system and three (3) categories of users, which include: doctor, nurses and record officer. Each category of user performs both read and write operations on the system based on predefined set of rules that determines what they can do. The major modules of the application include the Record, Nurse, and Doctor module.

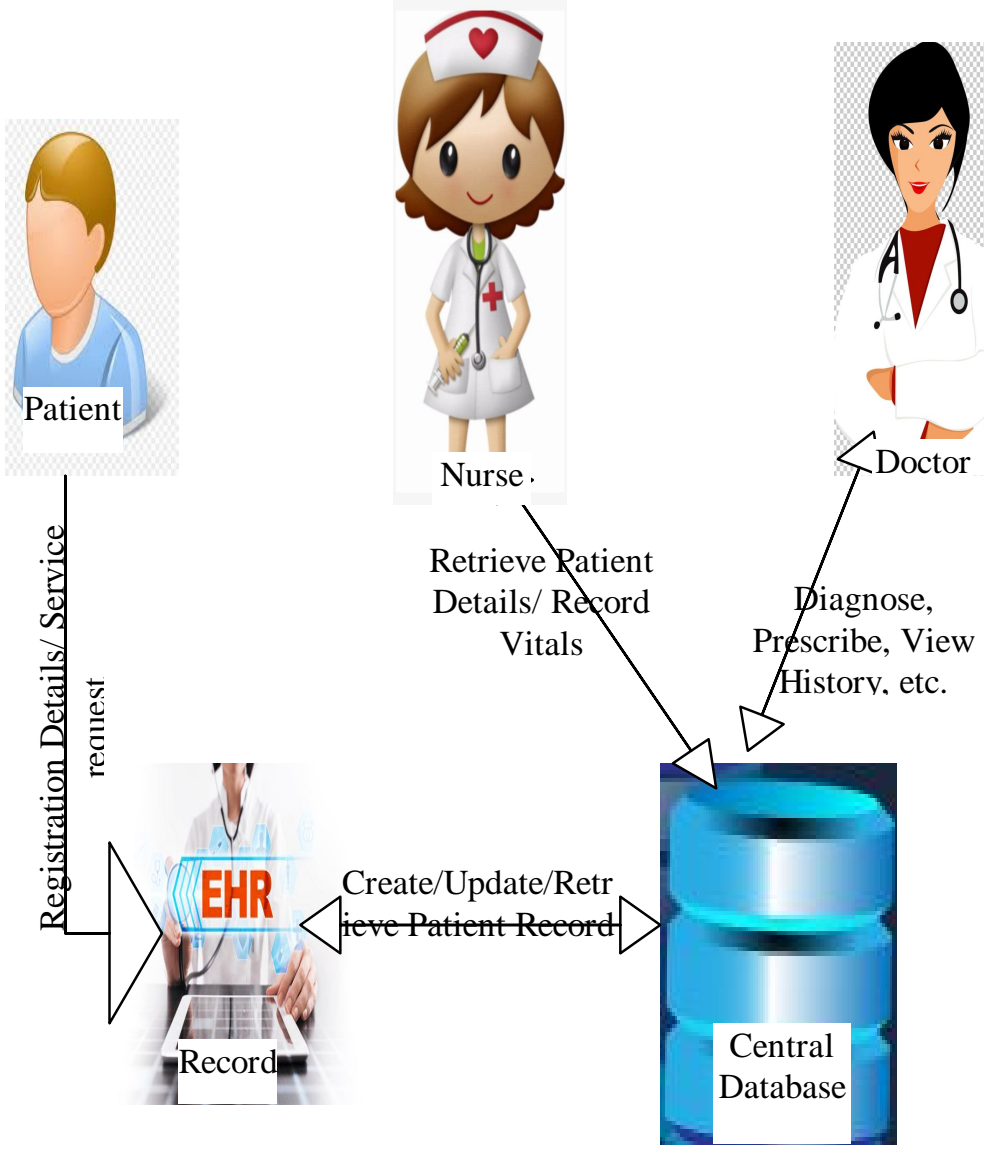

Figure 1: Architecture of the Health Information Record Management System

\section{The Record Module}

The record module manages patient records. This include the creation and assignment of unique identifier for patients, update of patient record (personal data section) and generation of reports on patient as well as various operations that relates with patients. The record module is responsible for access management on each patient record in order to maintain data integrity and consistency across clinics.

\section{The Nurse Module}

The nurse module manages the activities of nurses on the system. Nurses are responsible for administering emergency procedure to patient if need be and also record the patient's vitals before sending the patient record to the doctor's desk. The nurses' module extracts from the database, the list of patient waiting to see doctor and present the list to the nurse. It also keeps lock on record which is currently being attended to in order to enforce data integrity. The module also makes a record visible on the doctor's desk after the patient has been attended to by the nurse.

\section{The Doctor's Module}

The doctor's module manages operation of doctors within the system. Records of patient that desires to see the doctor are made available through the doctor's module after such record has been treated by a nurse. The doctor is presented with a list of patient waiting to be attended to. A user in the category of doctor can then select a patient to be attended to. The module retrieves the patient's details as well as diagnosis history of such patient. The module also allows the doctor to supply complaints by patient, symptoms observed, tests prescribed or conducted, medication or therapy prescribed or administered as well as dosage where applicable. Lock on patient record is removed and such record is made available to the record unit on completion.

\section{b. System Users}

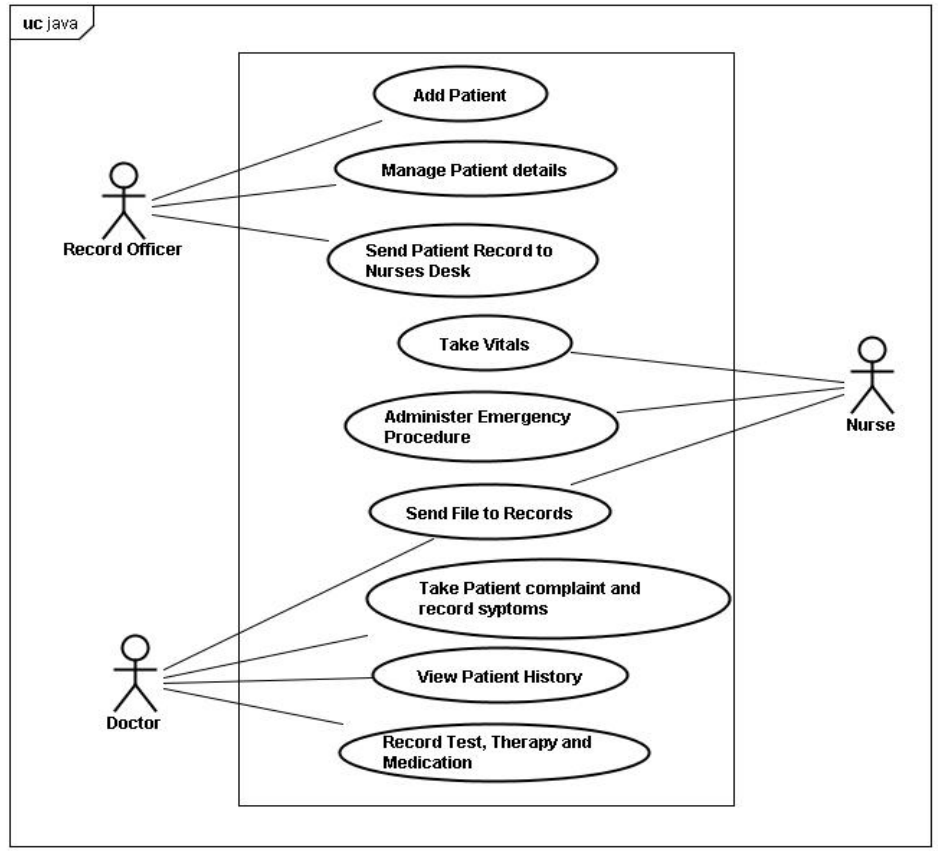

Figure 2: Use Case diagram for the Hospital Health Record Management System 
The proposed system has three (3) main users, which include: doctors, nurses and record officer. The role of each category of user is summarized in the use-case diagram in Figure 2.

Procedure of servicing a patient is initiated when the patient registers with the Record Unit of the Hospital. Subsequent visit by such patient will then require that the patient seeking medical attention presents his/her hospital number which is then used to retrieve the patients file and sent to appropriate quarter. Patient record sent to the Nurse desk can be returned to the record unit after vitals have been taken if there is no need for the patient to see doctor. Otherwise, the record is sent to the doctor's desk and returned to the record unit thereafter.

\section{SYSTEM IMPLEMENTATION}

The system implementation section makes the product available to end users, which are the major stakeholders within the hospital community. The implementation entails the hardware and software requirements for the proposed system, choice and justification of tools for implementation, as well as a detailed operation procedure for the developed system. A system is defined in terms of five major components which include: hardware, software, procedure, data, and people. Sometimes, the list does include network or communication media. This section of the report presents the recommended hardware and software requirements for smooth running of the system

\section{a. Hardware Requirements}

The developed system relies on a 3-tier web-based architecture which comprises of the server, middleware and the front end. The application server is expected to house the program while client access the application via browser. In order words, the application can be hosted on a shared hosting plan with any web hosting service provider with hosting plan that offers a minimum of 20GB Bandwidth per annum, $20 \mathrm{~GB}$ file storage space, 1 database, and support for email services. However, the hospital can decide to host the application locally on a server with the following recommended settings:

Table 1: Hardware Requirements

\begin{tabular}{|l|l|}
\hline \multicolumn{1}{|c|}{ Item } & \multicolumn{1}{c|}{ Specification } \\
\hline Processor & $\begin{array}{l}\text { Intel Dual Core/Quad Core/Core i5 } \\
\text { processor }\end{array}$ \\
\hline Memory & 4 GB RAM \\
\hline Hard Disk & $\begin{array}{l}\text { 1GB HDD space for application, DBMS, } \\
\text { database and other files }\end{array}$ \\
\hline $\begin{array}{l}\text { Network } \\
\text { Interface Card }\end{array}$ & 10/100 MBPS Network Interface Card \\
\hline Display & 17” Display \\
\hline Backup Drive & $\begin{array}{l}\text { 500GB External Hard Disk for regular } \\
\text { data backup }\end{array}$ \\
\hline
\end{tabular}

On the client side, any device such as PDA, mobile phones, laptops or desktop can be used to access the application. However, a system with the following configuration is recommended.

Table 2: Hardware Requirements

\begin{tabular}{|l|l|}
\hline \multicolumn{1}{|c|}{ Item } & \multicolumn{1}{c|}{ Specification } \\
\hline Processor & Intel Dual Core $2.0 \mathrm{GHz}$ processor \\
\hline Memory & $2 \mathrm{~GB}$ RAM \\
\hline Hard Disk & 30MB HDD space for application \\
\hline $\begin{array}{l}\text { Network } \\
\text { Interface Card }\end{array}$ & Wireless Network Card \\
\hline Display & 17 ' Display \\
\hline
\end{tabular}

In addition, a $2.4 \mathrm{GHz}$ or $5 \mathrm{GHz}$ Wireless Router or Wireless Access Point is required to provide connectivity for all the system on the network if the local hosting option is implemented while internet access is required for all system on the network if the shared hosting option is adopted.

\section{b. Software Requirements}

The application runs on a web server such as APACHE Tomcat and the recommended operating system on the server is Linux while the client requires a web browser such as Google Chrome, Mozilla Firefox or Opera running on any Operating System.

\section{c. Choice of Programming Language}

While there exists many programming languages for application development, the choice of language in this research is PHP and MySQL. PHP is a fast and feature-rich open source scripting language used to develop Web Applications or Internet / Intranet Applications while MySQL is a powerful open source database server built based on a relational database management system (RDBMS) and is capable of handling a large concurrent database connection. When combined together, very powerful and scalable Web / Internet / Intranet Applications can be developed. PHP and MySQL are Open Source, meaning that they are free development tools, and there is a large community of dedicated volunteer programmers who contribute to make improvements and are continuously adding features to it. Combination of PHP and MySQL for application development offers clean and simple usability, complex functionality, speed, power and scalability.

\section{OPERATIONAL PROCEDURE}

The health record management system developed captures four categories of users, which include the system administrator, the record officer, the doctor and the nurse. Each category can have one or more staff added to the system. Each user category perform different role within the system. The sub-sections below highlight the basic operations of each user category. 


\section{a. System Administrator}

The system administrator is expected to be a member of staff of the health institution, either employed solely to manage and oversee the record management system or an administrative staff trained to carry out the role of an administrator. Major role of the administrator is to manage other categories of user. In order to access the application, all categories of user are expected to supply their authentication credentials at the login screen which can be access by pointing the address bar of the browser to the homepage of the application as shown in Figure 3.

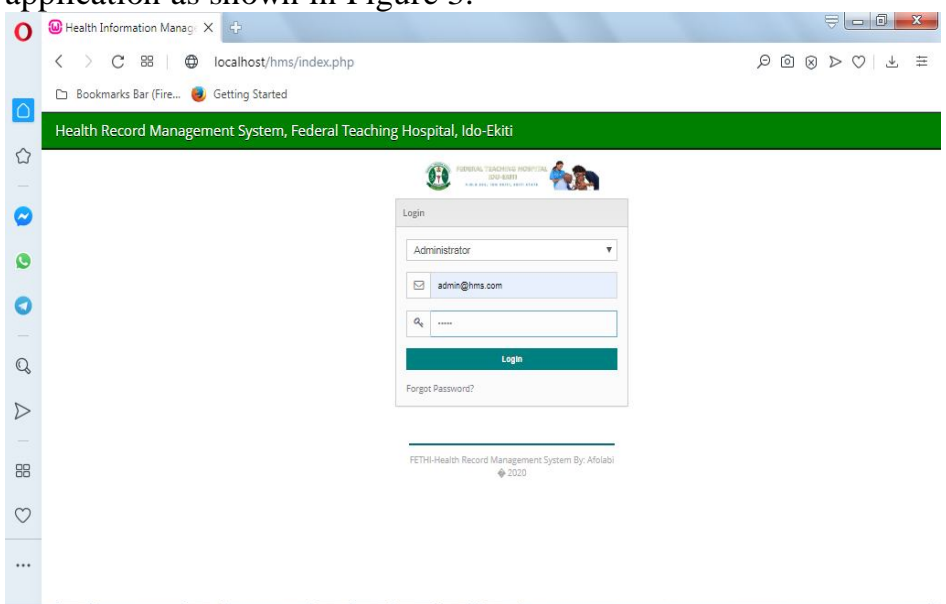

Figure 3: Application Login Page

Each user is expected to select the user category, and then supply the username and password. If the system administrator is successfully validated, the administrator dashboard is displayed as shown in Figure 4.

clicks on the Department button on the dashboard or use the link on

the sidebar. This opens a new page where department settings can be carried out as shown in Figure 5.

The department settings page shows by default the list of departments that have been added to the system. The list of department displayed in tabular form can be sorted dynamically and can easily be searched using the search facility provided on the page. To register a new department, the administrator clicks on the "Add department" tab and a new form is displayed as shown in Figure 6.

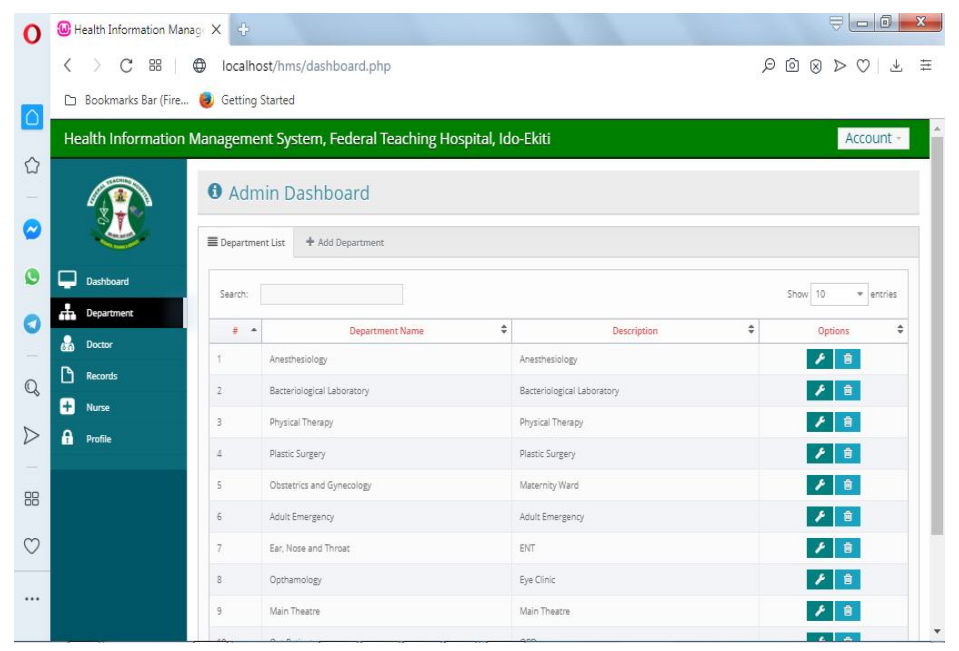

Figure 5: Administrator Settings- Department List.
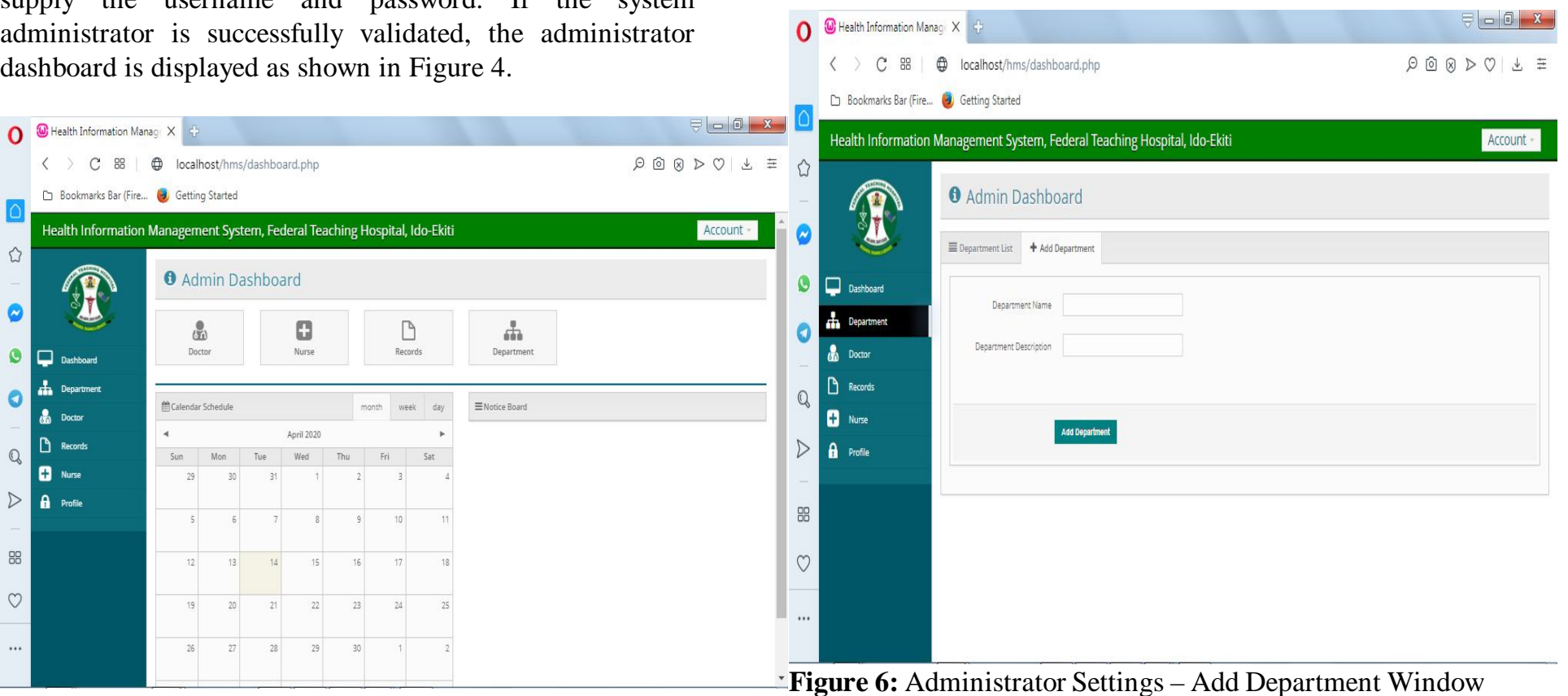

Figure 6: Administrator Settings - Add Department Window

\section{FIGURE 4: SYSTEM ADMINISTRATOR'S DASHBOARD}

The dashboard provides link to other pages where the administrator can perform his roles such as adding, deleting or updating record of doctors, nurses, record officer and department. To add a new department, the administrator
After a successful registration of department, the administrator can modify or delete department, if need be. This can be achieved by click of the "spanner" icon or the "bin" icon associated with each record as shown in Figure 5. Figure 7 shows the Department Update form. 


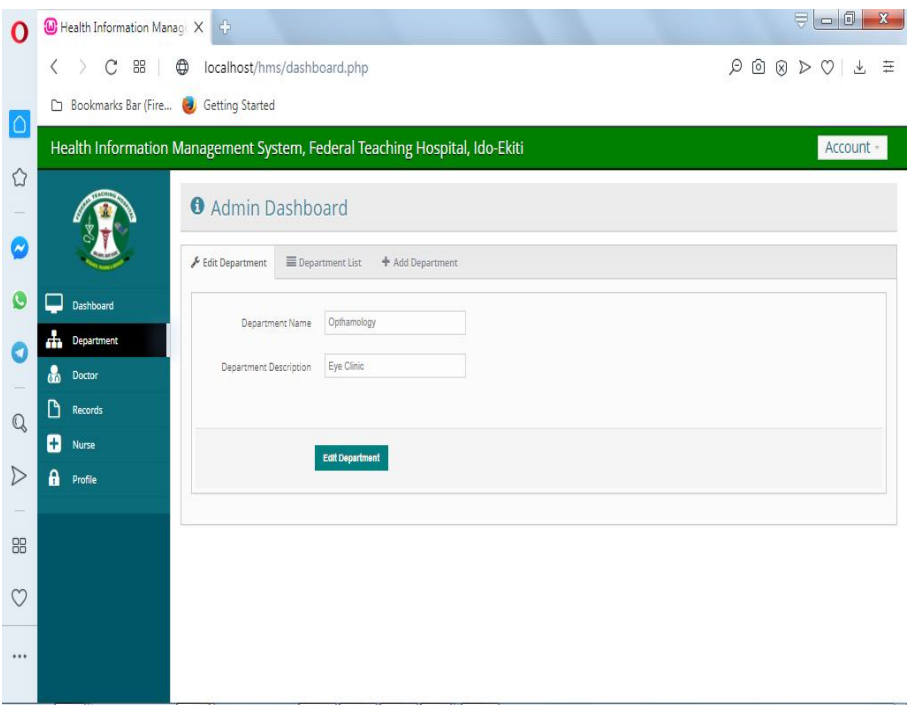

Figure 7: Department Update form

However, to delete a department, the system displays a confirmation box in order to ascertain the administrator is not acting in error. Aside managing other users within the application, the administrator is also equipped with the privilege of updating his/her profile and as well change the password in case they perceived that it might have been compromised. This feature of profile management is also available to other categories of user. Figure 8 shows the profile update window.

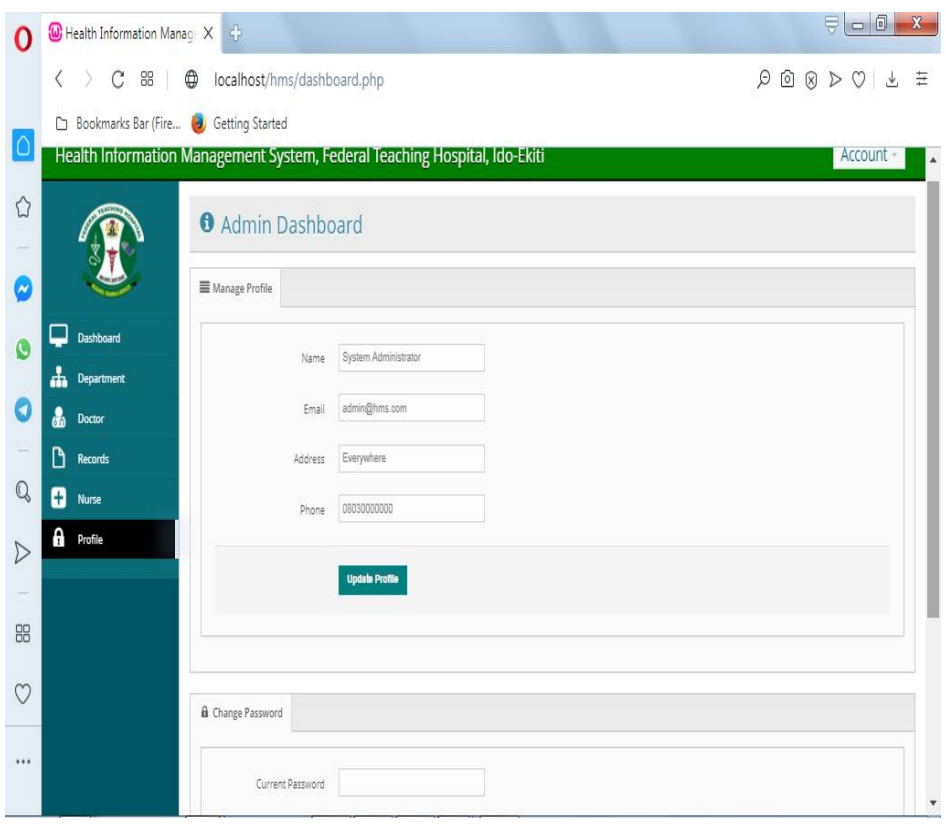

Figure 8: Profile Update Window

To add other categories of system user, the administrator clicks on the corresponding button or link. Figures 9, 10 and 11 show screenshots for adding, modifying and viewing list of doctors by the system administrator. The structure of the forms for other categories of user is the same with that of the doctor as depicted in Figures 9, 10 and 11.

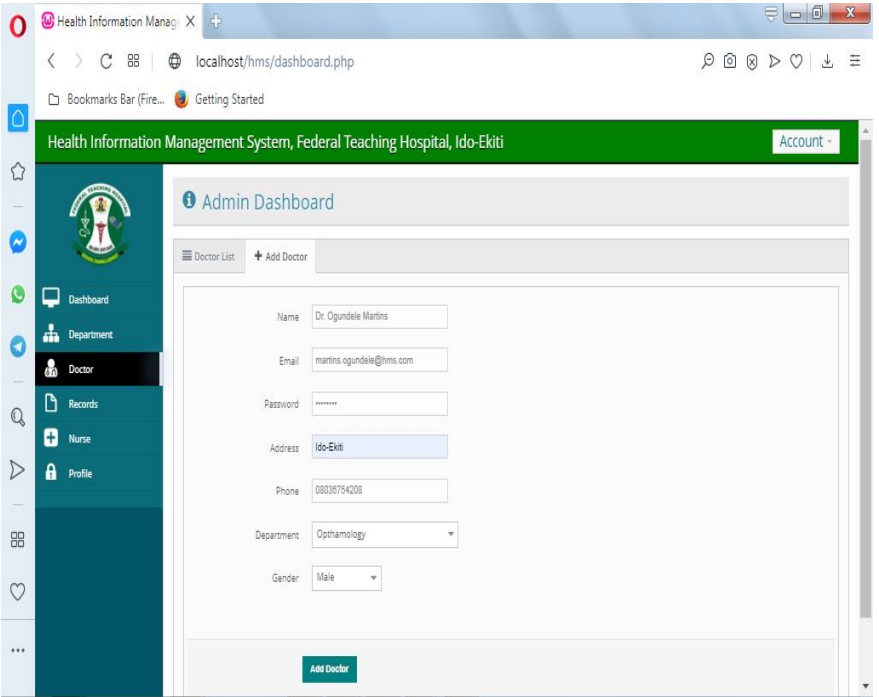

Figure 9: New doctor registration window
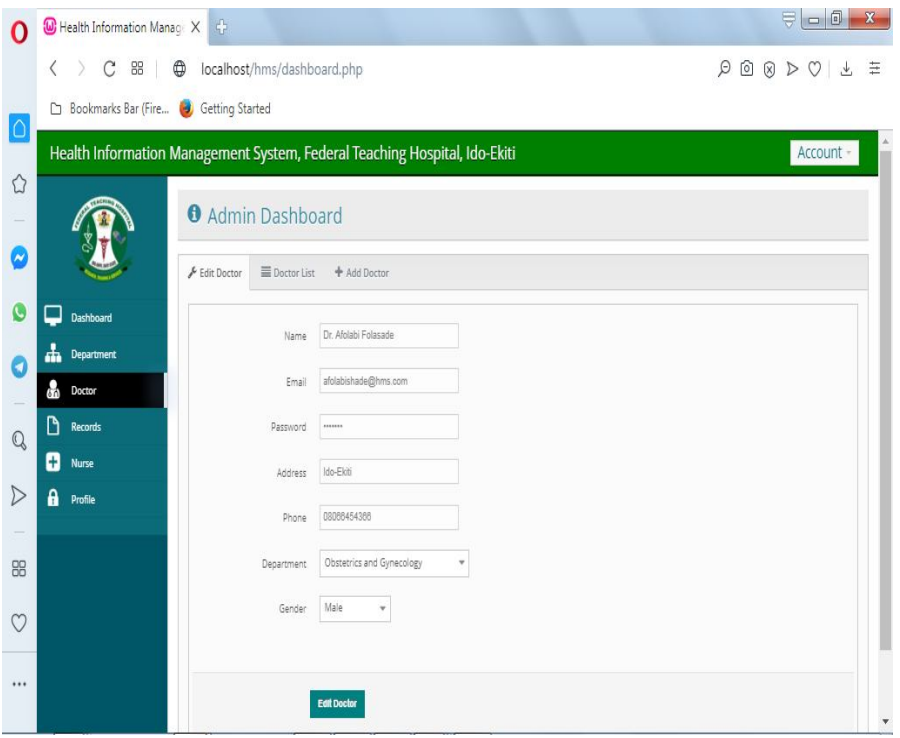

Figure 10: Doctor Registration details modification window

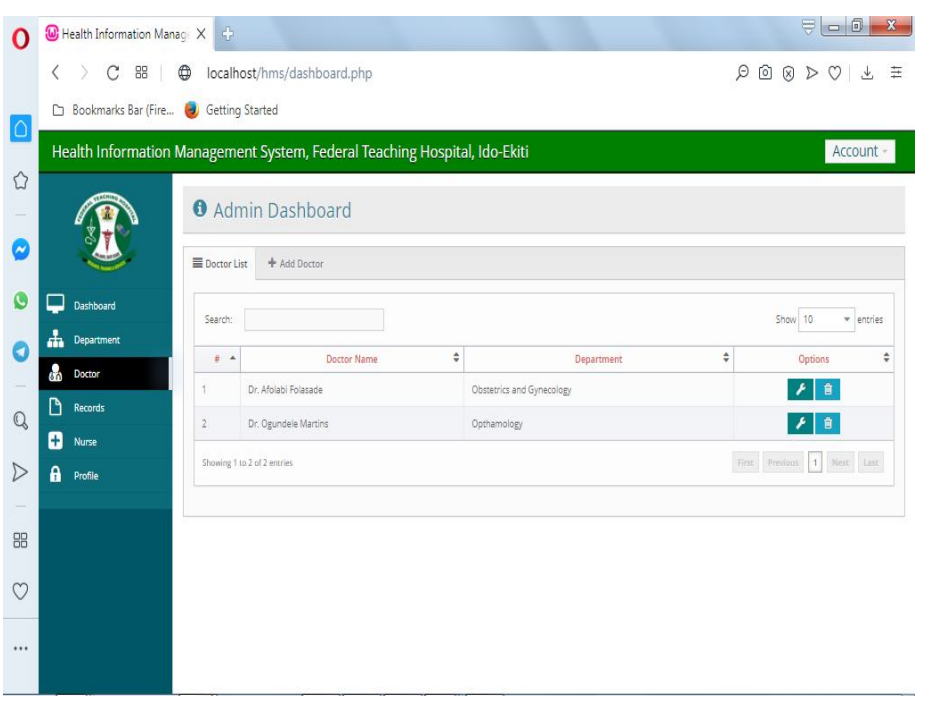

Figure 11: Registered Doctors' List 


\section{b. Records}

The record unit is saddled with two major tasks which include: Patient Management and Appointment Scheduling. The management aspect of patient record involves: registration of new patients, and update or deletion of patient record. Figure 12 shows the Patient Registration Form while Figure 13 shows the list of registered patients. The administrator can click on the "spanner" icon to modify or the "bin" icon to delete record.

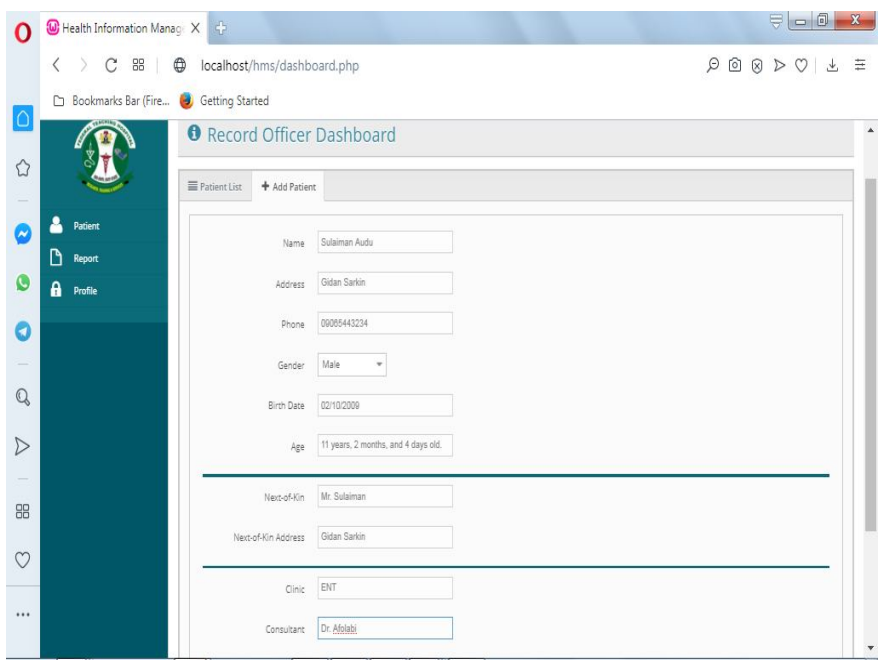

Figure 12: Patient Registration Page (by record officer)

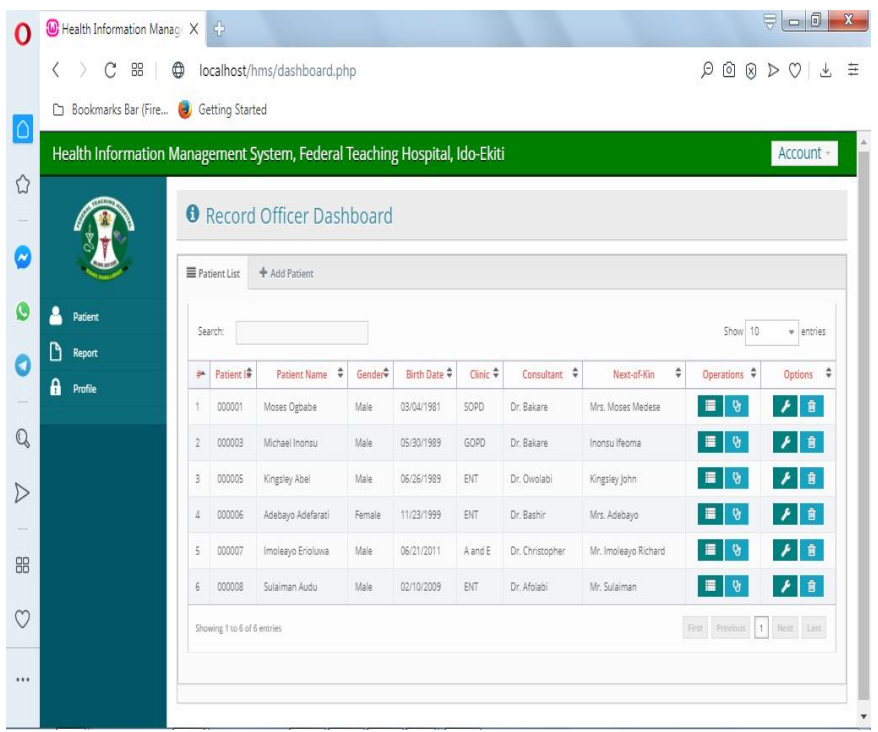

Figure 13: List of Registered Patients

From the Table displayed in Figure 13, it can be observed that there is a column for "Operation". The operation column provides two buttons. The first button shows file transfer history for the associated patient record. While the second button sends the file to the nurse pool after confirmation by the record officer. Figure 14 shows the file transfer history and status of a selected patient.

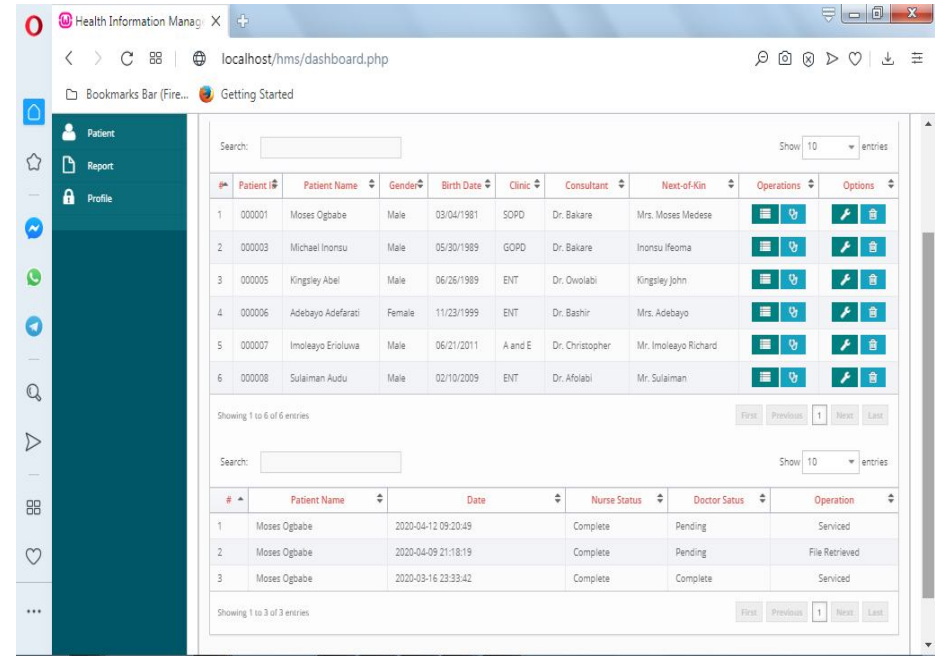

Figure 14: File transfer history for selected Patient.

From the file transfer history table, the Record officer is empowered to retrieve the record peradventure the patient cancels his/ her appointment. The record officer can also view report of files issued on daily basis. This can be achieved by clicking on the report link on the sidebar. The record officer then selects the date and the application pulls all record for the selected day. This include the file number, date and time the file was issued out, status of the file with nurses and doctor that are expected to attend to them. Figure 15 shows a sample report generated.

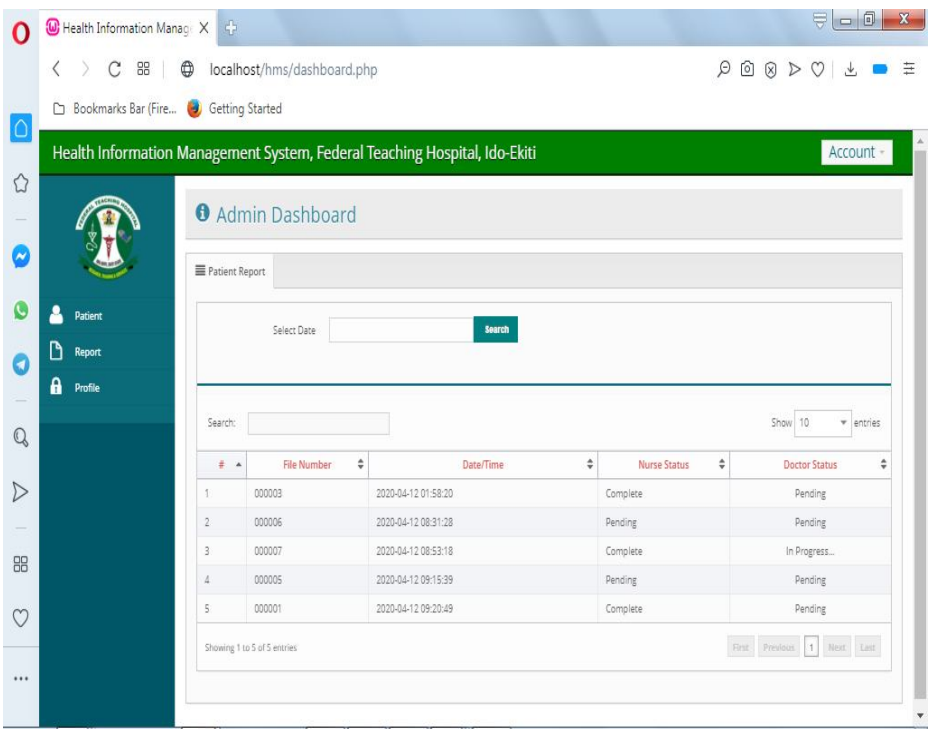

Figure 15: Sample daily file transfer report

\section{c. The Nurse}

The nurse as an entity within the system is saddled with the role of taking patients' vitals and updating such record before they are being transferred to the Doctor's desk. When a user logs in as a Nurse, they are presented with a pool of Patients' records (without details) waiting to see the doctor. The Nurse can then select a patient from the pool to attend to. Field 
where the nurse can supply vitals is provided on the displayed form. For emergency cases, probably when a child is convulsing and the Nurse is required to administer emergency procedure, such can also be recorded before submission to the Doctor's desk. Figures 16, and 17 show the list of patient waiting to see doctor, and vitals registration page respectively.

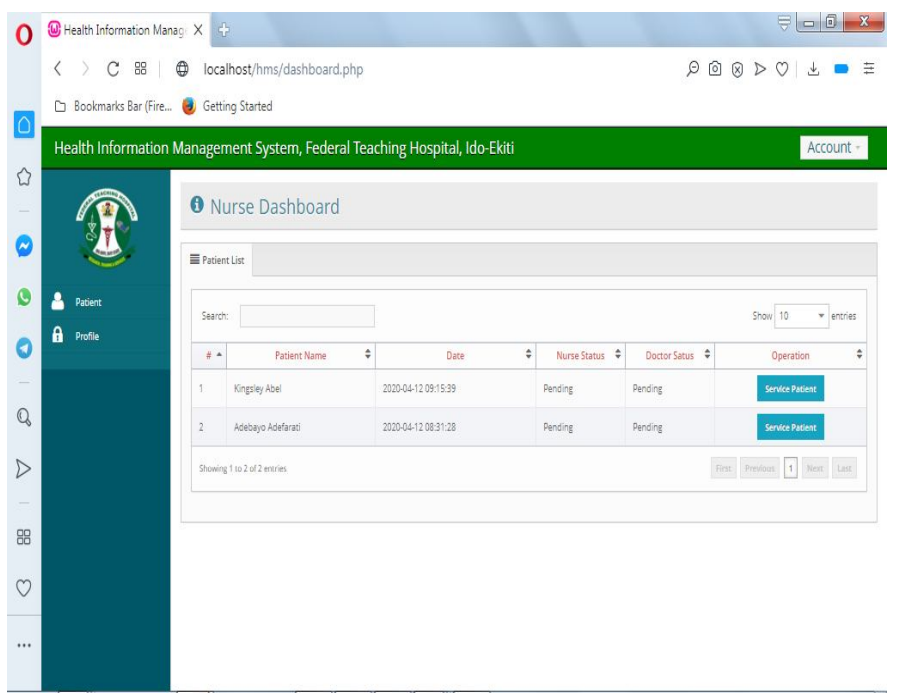

Figure 16: List of Patient waiting to see Doctor

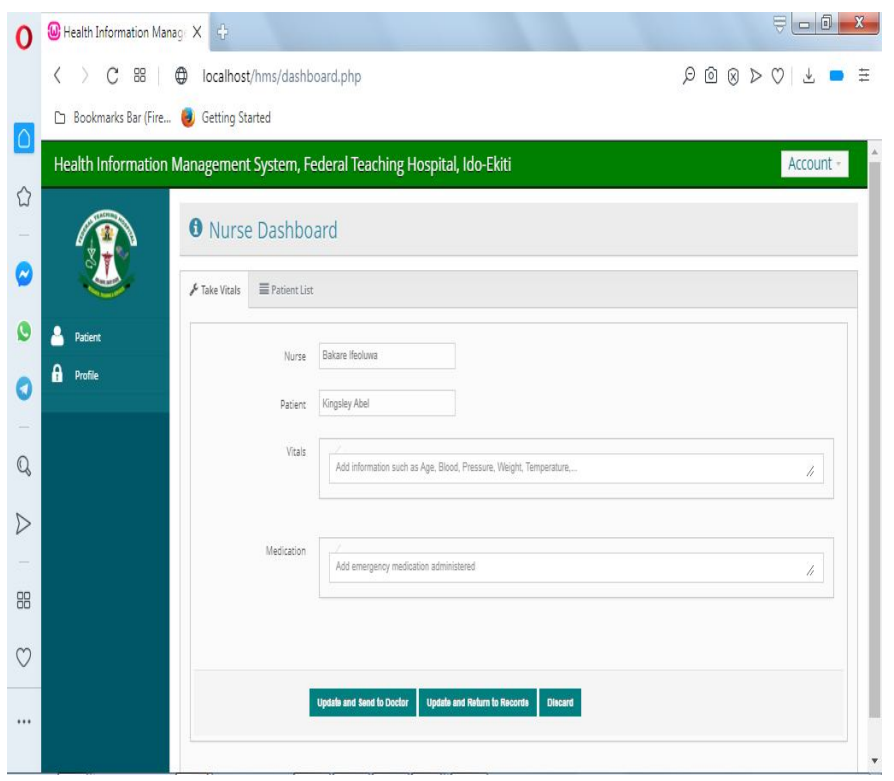

Figure 17: Vitals Entry Screen for Nurses

After successful entry of vitals, the nurse can send the document to Doctor's pool, send it back to Records or Discard (return to Nurses' pool without modification).

\section{d. The Doctor}

The doctor's panel is similar to the Nurses' panel however with elevated privilege that allows the doctor to supply further details such as patient's complaint, symptoms, diagnosis, prescribed tests, administered and prescribe drug or therapy.
Once the doctor login into the application, the list of patient that have been attended to by the nurse is displayed awaiting doctor as shown in Figure 18. The doctor selects a patient from the list and the data entry page is displayed as shown in Figure 19. Figure 19 shows the doctor's page. In the data entry page, the doctor has access to the patient's history, which includes information supplied by the nurse. It is worthy of note that once a patient has been selected by a doctor, a lock is maintained by the application so that the record is no longer available to other doctors at the same time. If for any reason, the doctor could not complete reporting for a patient, the patient record will be available on the list with doctor's status as In Progress.

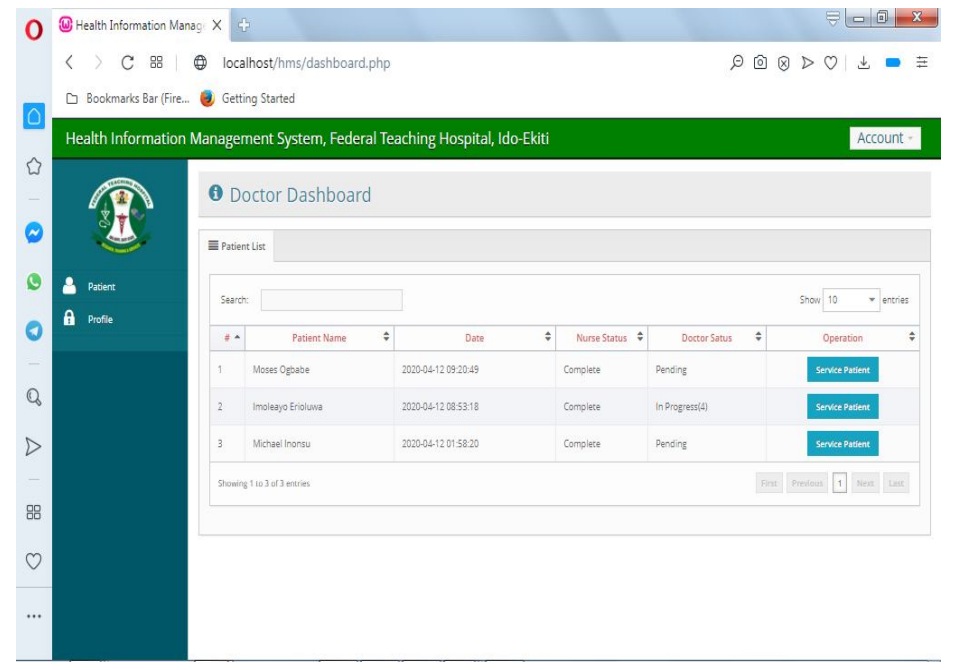

Figure 18: Doctors' Landing Page with patient list

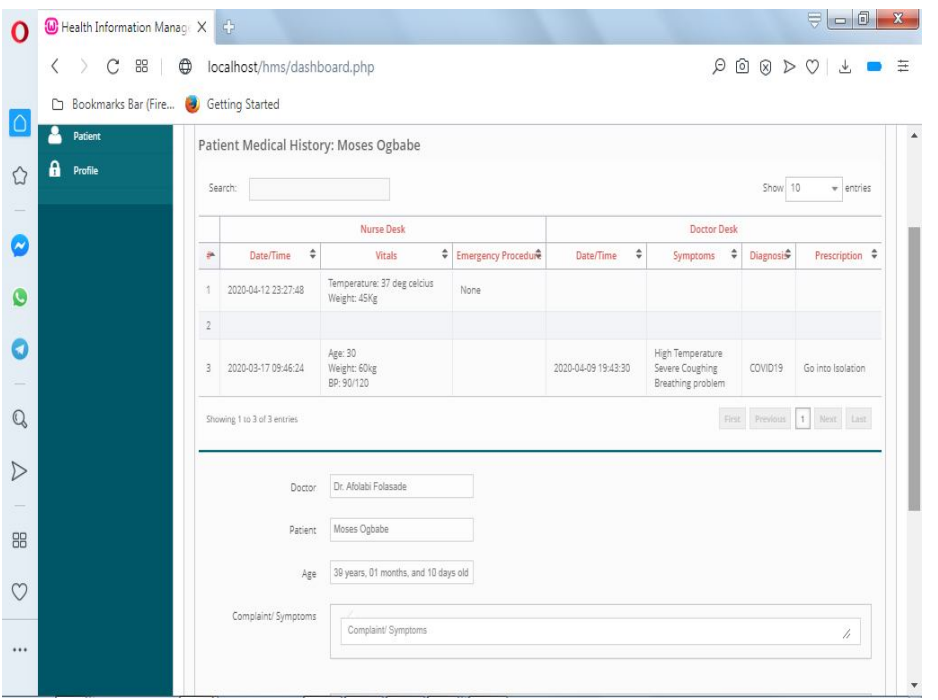

Figure 19: Doctor's documentation page

\section{CONCLUSION}

Health related information are generally classified as confidential and hence needs to be protected by health institutions. Present approach to file handling, in which junior cadre staff often move files between departments, is 
often subject to various degree of mishandling which could lead to loss of important document, leakage of confidential information, among others. The model proposed and implemented in this research addresses the issue of security and privacy in health information system and as well proffer other advantages such as easy storage and retrieval, easy transfer of patients 'records and also guarantee confidentiality of information at all stages using the access list and access control mechanism whereby level of users are defined and each user category has a clearly defined role within the system. In addition, the model has an auditing module that could provide answers to "who does what, when and to who". This feature deters disgruntled employee from carrying out unethical operations within the system. The developed application which was implemented as a web-based application also give room for mobility and makes the solution cost effective as no special hardware or software; since any device that has a browser and can access internet service is all that is required to use the developed application.

The system has also been developed with greater flexibility to allow for changes in logic and also developed with simple user interface and easy navigation to enhance usability.

In reference to the intent of this study and the research questions presented in motivation, the conclusions on the findings derived from the presented data and subsequent data analysis are as follows:-

i. The study reveals that the current paper based system has great security issues which have so many consequences ranging from data loss, data theft, financial loss to loss of human life.

ii. An electronic system based on a well-designed security model to access health information is capable of addressing the issue

iii. The developed application will help prevent consequences arising from poor security related to the paper based system.

Based on the above conclusion, the developed system presents the a reliable health information management system capable of providing adequate security for health information by granting data access to only authorized persons, limiting data access to only required information at any given time, providing only information the user is entitled to and prevention of data loss by providing adequate backups for existing data.

\section{REFERENCES}

[1] Ajit and Johnson (2010), Information Security and privacy in healthcare; current state of research.

International Journal Internet and Enterprise Management, Vol. 6, No.4, 2010.

[2] Adehor A.B and Burrell P.R., The integrated Management of Healthcare Strategies and Differential Diagnosis by Expert System Technology: a single- dimensional approach, World Academy of Sciences, Engineering and Technology, pp.533-538, 2008.

[3] Esmail; Marjam; Jebraeil \& Saghar., Security challenges in Healthcare cloud computing. Global Journal of Health Science; Vol. 9(3), No. 3, 2017.

[5] Mohammed N; \& Muhammed A. (2012). Health Information systems Concept and Technology.

[6] Olarewaju, R.F., Nor Ashikin Bte Ali; Othman Khalifa., and Azizah Abd Manaf. (2013). ICT in Telemedicine: conquering privacy and security issues in healthcare services.

[7] Olatunbosun K and Petirin Olayemi T., Expert System for Diagnosing Malaria and Typhoid, International Conference of Science, Engineering and Environmental Technology, 2(44), pp. 341-346, 2017.

[8] Oladipo O, Olayinka C.T and Popoola O.L, Mobile Compactable Expert System for the Treatment of Typhoid Fever in Developing Countries, International Journal of Computer Applications, Vol5-No2, Nov2014, pp. 16-19.

[9] Oguntimilehin A., Abiola O.B., Olatunji K.A., Computer Aided Diagnostic Systems for Managing Typhoid Fever: A Review of Diagnostic Techniques, International Journal of Computer Applications, Vol. 126, No.6, pp 24-29, September, 2015. https://doi.org/10.5120/ijca2015906071.

[10] Oguntimilehin A., Adetunmbi O., and Osho I., Towards Achieving Optimal Performance using Stacked Generalization algorithm: A Case Study of Clinical Diagnosis Malaria Fever, The International Arab Journal of Information Technology, Vol.16, No.6, pp. 1074-1081, November 2019.

[11] Oguntimilehin A., Abiola O.B., Olatunji K.A., Computer Aided Diagnostic Systems for Managing Typhoid Fever: A Review of Diagnostic Techniques, International Journal of Computer Applications, Vol. 126, No.6, pp 24-29, September, 2015. https://doi.org/10.5120/ijca2015906071

[12] Oguntimilehin A., Babalola G.O and Olatunji K.A., A Clinical Diagnostic Model Based on Supervised Learning, International Journal of Advanced Trends in Computer Science and Engineering, Volume 8, No. 3, pp. 949-953, May-June, 2019

https://doi.org/10.30534/ijatcse/2019/94832019.

[13] Oguntimilehin A., Olatunji K.A., Abiola O.B., A Computer Based Intelligent System for Managing Typhoid Fever, International Journal of Advanced Trends in Computer Science and Engineering, Vol. 9, No.1, pp 528-532, January-February,2020.

[14] World Health Organization (WHO), Immunization, Vaccines and Biologicals, December, WHO, 2019. 